\title{
Signatures of Post-Glacial Genetic Isolation and Human-Driven Migration in the Dothistroma Needle Blight Pathogen in Western Canada
}

\author{
Arnaud Capron, ${ }^{1}$ Nicolas Feau, ${ }^{1, \dagger}$ Renate Heinzelmann, ${ }^{1}$ Irene Barnes, ${ }^{2}$ Andy Benowicz, ${ }^{3}$ Rosie E. Bradshaw, ${ }^{4}$ \\ Angela Dale, ${ }^{1,5}$ Kathy J. Lewis, ${ }^{6}$ Timothy J. Owen, ${ }^{6}$ Richard Reich, ${ }^{7}$ Tod D. Ramsfield, ${ }^{8}$ Alex J. Woods, ${ }^{9}$ and
} Richard C. Hamelin ${ }^{1,10, \dagger}$

\author{
${ }^{1}$ Department of Forest and Conservation Sciences, University of British Columbia, Vancouver, BC, V6T 1Z4, Canada \\ 2 Department of Biochemistry, Genetics and Microbiology, Forestry and Agricultural Biotechnology Institute (FABI), University of Pretoria, \\ Pretoria 0002, South Africa \\ ${ }^{3}$ Alberta Agriculture and Forestry, 9920-108 Street, Edmonton, AB, T5K 2M4, Canada \\ ${ }^{4}$ School of Fundamental Sciences, Massey University, Palmerston North, 4410, New Zealand \\ ${ }^{5}$ SC-New Construction Materials, FPInnovations, Vancouver, BC, V6T 1Z4, Canada \\ ${ }^{6}$ Ecosystem Science and Management Program, University of Northern British Columbia, Prince George, BC, V2N 4Z9, Canada \\ ${ }^{7}$ Natural Resources and Forest Technology, College of New Caledonia, Prince George, BC, V2N 1P8, Canada \\ ${ }^{8}$ Natural Resources Canada, Canadian Forest Service, 5320 - 122 St., Edmonton, AB, T6H 3S5, Canada \\ ${ }^{9}$ BC Ministry of Forests Lands and Natural Resource Operations and Rural Development, Skeena Region, Smithers, BC, V0J 2N0, Canada \\ ${ }^{10}$ Faculté de foresterie et géomatique, Institut de Biologie Intégrative et des Systèmes (IBIS), Université Laval, Québec, QC, G1V0A6, Canada \\ Accepted for publication 27 October 2020.
}

\begin{abstract}
Many current tree improvement programs are incorporating assisted gene flow strategies to match reforestation efforts with future climates. This is the case for the lodgepole pine (Pinus contorta var. latifolia), the most extensively planted tree in western Canada. Knowledge of the structure and origin of pathogen populations associated with this tree would help improve the breeding effort. Recent outbreaks of the Dothistroma needle blight (DNB) pathogen Dothistroma septosporum on lodgepole pine in British Columbia and its discovery in Alberta plantations raised questions about the diversity and population structure of this pathogen in western Canada. Using genotyping-by-sequencing on 119 D. septosporum isolates from 16 natural pine populations and plantations from this area, we identified four genetic lineages, all distinct from the other DNB lineages from outside of North America. Modeling of the population history indicated that these lineages diverged between 31.4 and
\end{abstract}

ABSTRACT
7.2 thousand years ago, coinciding with the last glacial maximum and the postglacial recolonization of lodgepole pine in western North America. The lineage found in the Kispiox Valley from British Columbia, where an unprecedented DNB epidemic occurred in the 1990s, was close to demographic equilibrium and displayed a high level of haplotypic diversity. Two lineages found in Alberta and Prince George (British Columbia) showed departure from random mating and contemporary gene flow, likely resulting from pine breeding activities and material exchanges in these areas. The increased movement of planting material could have some major consequences by facilitating secondary contact between genetically isolated DNB lineages, possibly resulting in new epidemics.

Keywords: evolution, forest pathology, fungal pathogens, genomics, population biology
Forest disease outbreaks are most often caused by introduced alien pathogens. In addition, climate change has been increasingly associated with outbreaks of endemic pathogens. In response, current breeding efforts in the Canadian provinces of British Columbia and Alberta have been incorporating assisted gene flow to climate-based seed transfer (CBST) policies to match reforestation seedlots with future climate predictions (MacLachlan et al. 2017). Little is known, however, about the impact of such transfer on facilitating disease outbreaks. Knowledge of these disease threats would be particularly important for assisted migration of lodgepole pine (Pinus contorta Dougl. ex Loud. var.

†Corresponding authors: N. Feau; nicolas.feau@mail.ubc.ca; and R. C. Hamelin; Richard.Hamelin@ubc.ca

Funding: This research was financially supported by the CoAdapTree Project (241REF), with funding from Genome Canada, Genome British Columbia, Genome Alberta (grant number 241REF), and Genome Québec (a full list of sponsors is available at https://coadaptree.forestry.ubc.ca/sponsors/).

*The $e$-Xtra logo stands for "electronic extra" and indicates that supplementary materials are published online.

The author(s) declare no conflict of interest.

(C) 2021 The American Phytopathological Society latifolia Engelm.), the most extensively planted tree species in British Columbia and Alberta, contributing approximately $45 \%$ of the annual planting in these two provinces (MacLachlan et al. 2017). Dothistroma needle blight (DNB) disease is caused by the fungal pathogens Dothistroma septosporum (Dorogin) M. Morelet and D. pini Hulbary (Drenkhan et al. 2016). D. septosporum, the more well-known pathogen, is often associated with accidental introductions through the trade of infected seedlings to the Southern Hemisphere, as a side effect of the installation of commercial pine plantations (Barnes et al. 2014; Bradshaw et al. 2019; Dubin 1965; Gibson et al. 1964). In Canada, DNB disease levels were relatively low until an unprecedented outbreak of the disease occurred in northwestern British Columbia, driven by climate change. This outbreak resulted in extensive tree defoliation and even mortality in both managed and natural stands of lodgepole pine beginning in the late 1990s (Woods 2003; Woods et al. 2005). In all, >90\% of stands surveyed had suffered some damage in the outbreak, with levels of infection ranging from trace to $100 \%$ and, in some cases, resulting in complete plantation failure (Woods 2003; Woods et al. 2005, 2016).

There is evidence to suggest that the DNB pathogen populations were at equilibrium with natural populations of lodgepole pine in western North America (Dale et al. 2011; Evans 1984; Welsh et al. 2009). However, dendrochronological studies showed that DNB 
outbreaks have occurred periodically for two centuries in British Columbia, the incidence and extent of these epidemics having increased since the 1940s (Welsh et al. 2009; Woods et al. 2005). Between 1949 and 1995, the Canadian Forest Service Annual Forest Insect and disease Survey monitored DNB incidence, reporting specific areas around Prince George in central British Columbia and Nelson in southeast British Columbia that were severely affected at the end of the 1970s and the early 1980s (van Sickle et al. 2001). The range expansion of $D$. septosporum and recent increases in disease incidence and severity have been attributed to both climate change and extensive plantations of lodgepole pine, the latter having greatly increased host abundance in British Columbia (Woods et al. 2005). Changes in key environmental factors such as increase in precipitation and warmer temperatures have directly affected the life cycle components and biological traits of D. septosporum, leading to the severe outbreaks observed in the past three decades in British Columbia (Welsh et al. 2009; Woods et al. 2005).

Population genetics studies have shed some light on the population structure across the global and local range of D. septosporum. This pathogen has a worldwide distribution, indicating that the pathogen can tolerate or adapt to different climatic conditions (Drenkhan et al. 2016). Population genetics analyses established that $D$. septosporum can be subdivided into distinct races or lineages (Barnes et al. 2014; Ennos et al. 2020). Populations from the Northern Hemisphere usually show high levels of genetic diversity. In contrast, Southern Hemisphere populations from Australasia, Africa, and South America collected mainly in plantations of $P$. radiata D. Don display a clonal structure consistent with a scenario of recent introduction with few founder individuals (Barnes et al. 2014; Bradshaw et al. 2019). On a local scale, the history of DNB has been influenced by recent introduction events or lineage diversification followed by outbreaks and local range expansion. For example, in Poland, the genetic structure of a local founder population was modified in $<10$ years by new reintroductions of the pathogen (Boron et al. 2019). In Scotland, the local DNB population infecting the native pine species $P$. sylvestris L. coexists with two epidemic lineages that have likely been introduced from continental Europe with $P$. nigra Arnold spp. laricio (Poir.) Maire and from Canada with $P$. contorta (Ennos et al. 2020; Mullett et al. 2017; Piotrowska et al. 2017). Finally, in the Kispiox Valley in northwestern British Columbia, sexual reproduction and epidemic clonality (defined as occasional spread of ephemeral clonal haplotypes) are both shaping the genetic structure of the populations found in the area affected by recent DNB outbreaks (Dale et al. 2011).

Regional distributions and epidemiology of D. septosporum are shaped by local climatic conditions (Woods et al. 2016). However, several other biotic, abiotic, and anthropogenic factors such as an increase in host abundance (Woods 2003) or the introduction of more virulent haplotypes may also be important drivers of DNB epidemics (Ennos et al. 2020; Piotrowska et al. 2017). Recent DNB outbreaks in British Columbia, as well as the discovery of the pathogen in nurseries and plantations in Alberta (Feau et al. in press), raise questions about the relationship between the British Columbia and Alberta populations. Reports of the pathogen in Alberta are sporadic and, thus far, only associated with anthropogenic activities related to seed orchards, nurseries, and plantations; the disease has not yet been observed in natural stands (Feau et al. in press). This could point to a recent introduction of the pathogen into this area, possibly from a British Columbia source or, alternatively, any other area where the disease is present. The general objective of the current study was to explore the diversity and structure of D. septosporum populations in western Canada to address these questions (such as origin) by using genotyping-by-sequencing (GBS) to assess genome-wide genetic variation. More specially, we (i) investigated the relatedness between DNB populations sampled in British Columbia and Alberta, (ii) characterized the connectivity of these populations with other populations of North America and other continents, and (iii) assessed their demographic and evolutionary history to test the hypothesis of recent introductions through tree exchanges. Our findings could affect future deployment of lodgepole pine seedlots used in reforestation.

\section{MATERIALS AND METHODS}

Isolate collection and DNA extraction. Collections of D. septosporum were made at various times over the last 15 years from lodgepole pine (P. contorta var. latifolia) and lodgepole $\times$ jack pine hybrids $(P$. contorta $\times P$. banksiana Lamb.) in natural stands, provenance tests, clone banks, and seed orchards in two regions in British Columbia and one in Alberta (Table 1). In total, 196 isolates ( 1 per tree) were obtained by following the isolation protocol described by Dale et al. (2011). Specifically, in 2012 to 2013, 53 isolates were obtained from needles of lodgepole pine and lodgepole $\times$ jack pine hybrids at five research sites in northern Alberta close to the city of Edmonton, 77 were obtained from three lodgepole pine plantations in the region of Prince George in central British Columbia, and 25 were obtained from lodgepole pine located in two plantations in the Kispiox Valley region close to Smithers in northwestern British Columbia. For these isolates, axenic cultures were grown on Dothistroma medium (Bradshaw et al. 2000) at room temperature for 3 weeks and the mycelium was collected and frozen before performing DNA extraction. Forty-one DNA samples obtained in 2004 to 2005 from DNB individuals isolated from four natural lodgepole pine stands and two plantations located within the primary range of the DNB epidemic in the Kispiox Valley region of British Columbia were added to this collection (Dale et al. 2011).

GBS. For each culture, D. septosporum identification was confirmed by sequencing the ribosomal internal transcribed spacer region (ITS) and comparing it with the ITS sequence of the D. septosporum ex-neo-type culture CBS H-22299 (GenBank accession number KU948400), as described by Feau et al. (in press). Total genomic DNA of the 196 D. septosporum cultures obtained was extracted from ground mycelium using the Qiagen DNeasy Plant Mini Kit according to the manufacturer's instructions (Qiagen, Valencia, CA, U.S.A.) and eluted in $50 \mu \mathrm{l}$ of sterile Milli-Q water. GBS was then conducted at the IBIS platform of Laval University (http://www.ibis.ulaval.ca/en/services-2/). Sequencing libraries were prepared according to the protocol described by Elshire et al. (2011) with the selective primers and minor modifications described by Sonah et al. (2013) and sequenced on an Ion Proton sequencer and P1 chips (Thermo Fisher Scientific, Waltham, MA, U.S.A.).

GBS data processing. The quality of GBS reads was checked with FastQC (Andrews 2010) before being processed with Trimmomatic (Bolger et al. 2014) and FASTX-Toolkit (Gordon and Hannon 2012) for demultiplexing, adaptor clipping, and trimming. High-quality trimmed reads were aligned to the NZE10 v1.0 reference genome (de Wit et al. 2015; Ohm et al. 2012) using BWA with default parameters (Li and Durbin 2009). Singlenucleotide polymorphisms (SNPs) were called using the mpileup caller of bcftools ( $\mathrm{Li}$ 2011) with the -bcvg option and ploidy option set to one (because most of the lifecycle of D. septosporum is haploid). Final filtering was performed using VCFtools (Danecek et al. 2011) with the following parameters: minimum genotype quality of 20, a minimum depth of four reads, and maximum missing data of $5 \%$ per site. The resulting VCF file contained 10,879 callable nucleotide positions, including 1,491 biallelic SNPs. The original dataset of $196 \mathrm{D}$. septosporum isolates genotyped by GBS was reduced to 119 isolates after discarding 13 isolates that failed genotyping and 64 isolates identified as clones (using a $99.5 \%$ identity threshold for clonality).

Nucleotide diversity and population differentiation. We assessed the genetic diversity of $D$. septosporum populations from western Canada by using the data generated with GBS. Population 
differentiation was assessed through the hierarchical analysis of molecular variance (AMOVA) among the three regions (i.e., Alberta, Prince George, and Kispiox Valley) and among and within the 16 populations in the three regions, nucleotide diversity $(\pi)$, and fixation index $\left(F_{s t}\right)$ with Arlequin ver. 3.11 (Excoffier and Lischer 2010). The molecular variance components and $F_{s t}$ values (i.e., Arlequin's $\varphi$ statistics) were tested by a nonparametric test with 1,000 permutations.

Genetic structure analysis of $D$. septosporum populations from western Canada. Multivariate analysis and modelbased clustering methods were used to determine the number of genetic clusters represented in our sample set. The population structure was evaluated using principal component analysis (PCA) with SNPrelate (Zheng et al. 2012) and a model-based approach to estimate individual admixture coefficients with sNMF (Frichot et al. 2014). sNMF runs were executed with 1,000 repeats for each $K$ ranging from 2 to 10 . The average cross-entropy for each $K$ value was calculated by masking $10 \%$ of the original dataset to guide the choice of the number of ancestral populations. CLUMPP was used to summarize and visualize the sNMFs outputs (Jakobsson and Rosenberg 2007). Finally, a neighbor-joining tree with bootstrap support (BS) (1,000 replicates) was created based on a Euclidean pairwise distance matrix with the function aboot of the $\mathrm{R}$ package poppr v2.8 (Kamvar et al. 2014; R Core Team 2013).

Genealogy of DNB isolates from Canada. Phylogenetic analyses were conducted to determine whether the main clusters identified in the genetic structure analyses of the Canadian isolates represent new and distinct independent lineages by making comparisons with other lineages of $D$. septosporum identified in a previous study (Bradshaw et al. 2019). The whole-SNP dataset was used to reconstruct the genealogical relationships between 119 isolates of $D$. septosporum from this study; 18 D. septosporum isolates representing lineages from North America, South America, Europe, Africa, Asia, and New Zealand (available in the Sequence Read Archive under accession number SRP103141) (Bradshaw et al. 2019); and the D. pini isolate CBS 116487 (Bradshaw et al. 2019; Ozturk et al. 2017) used as the outgroup. Illumina reads generated from these additional genomes were mapped on the reference NZE10 v1.0 genome using the BWA/mpileup/bcftools pipeline as described above. Variants were matched with the 1,491 biallelic SNPs obtained for the 119 Canadian isolates sequenced by GBS. This resulted in a new VCF file that contained 1,348 biallelic SNPs when the outgroup D. pini was added (i.e., 143 SNP loci missing in D. pini). Using a custom Python script (Python 2.7), the VCF file was converted to FASTA format that was used as the input data for the phylogenetic analyses. Maximum-parsimony and maximum-likelihood trees were reconstructed using PAUP ver. 4.0b10 (Swofford 2003) and RAxML (Stamatakis 2014), respectively. The shortest maximum-parsimony tree was identified by a heuristic search and 100 random additions of sequences; node support was examined using bootstrapping with 100 pseudoreplicates and the heuristic option with 100 random additions of sequences per pseudoreplicate. Phylogenetic reconstruction based on maximum likelihood was performed under the GTR model with a GAMMA parameter. BS at nodes was determined by 100 iterations.

Extent of sexual recombination and random mating within D. septosporum lineages. Because D. septosporum is a heterothallic fungus combining both sexual (supposedly rare) (Dale et al. 2011) and asexual reproduction in its lifecycle, we assessed the extent of sexual recombination and random mating within each of the four clusters (i.e., lineages) by calculating mating type frequencies and linkage disequilibrium. Each D. septosporum isolate was screened to determine mating-type idiomorphs with mating-type-specific primers following the method of Groenewald et al. (2007). A $\chi^{2}$ test was performed to determine whether mating type ratios differed significantly from a 1:1 ratio indicative of random mating. Linkage disequilibrium (i.e., allele frequency correlation $\left[r^{2}\right]$ ) (Hill and Robertson 1968) between pairs of SNPs $<100 \mathrm{~kb}$ apart was calculated with VCFtools (Danecek et al. 2011) on the dataset of 10,879 filtered loci (1,491 biallelic SNPs), excluding sites with minor allele frequencies $<10 \%$. Linkage disequilibrium was also estimated based on the distribution of the modified multilocus index of association $\left(\bar{r}_{d}\right)$ (Agapow and Burt 2001 ) on each of the $D$. septosporum scaffolds calculated using the ia function of the R package poppr v2.8 (Kamvar et al. 2014).

Demographic history of DNB lineages. The population history of the four clusters (i.e., lineages) identified in the

TABLE 1. Geographic origin and sample size of populations of Dothistroma septosporum collected in western Canada on lodgepole pine (Pinus contorta var. latifolia) and lodgepole $\times$ jack pine hybrids (P. contorta var. latifolia $\times$ P. banksiana) in this study

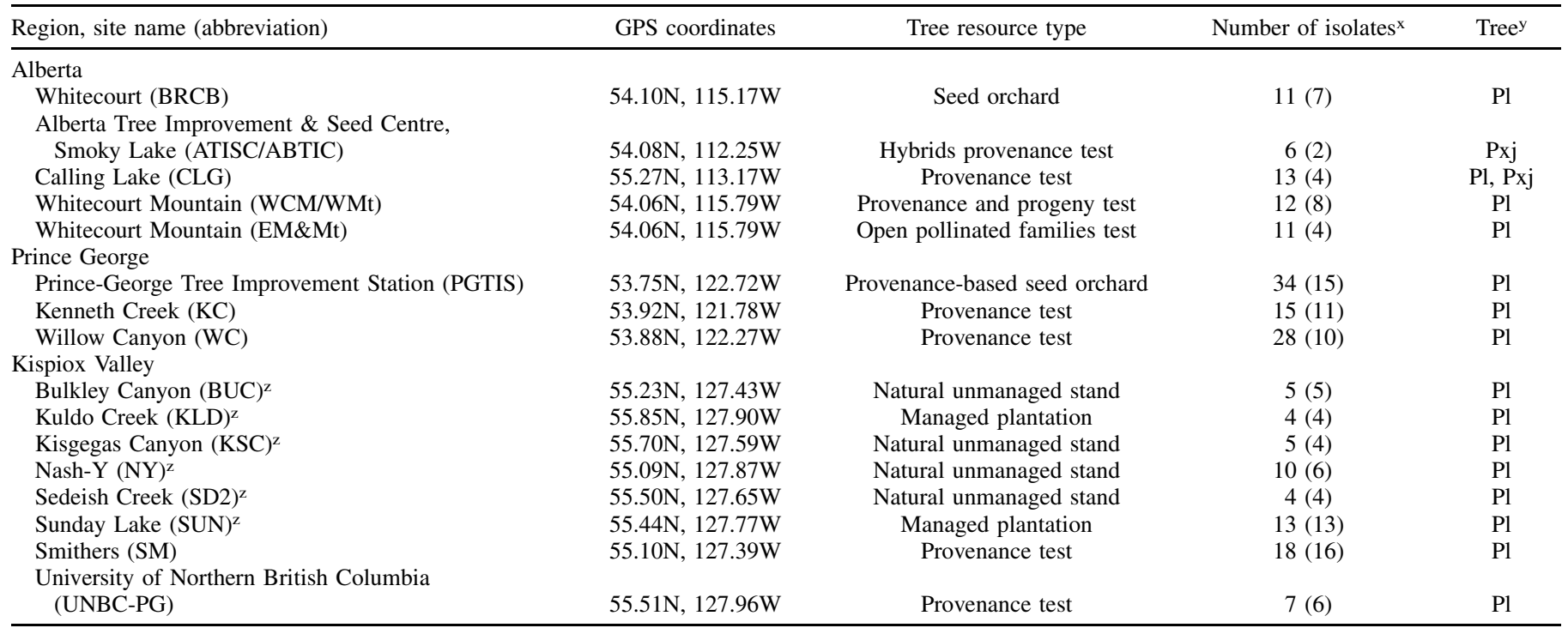

${ }^{x}$ Left: Number of D. septosporum isolates obtained; Right (between brackets): number of isolates successfully genotyped by genotyping-by-sequencing and retained after clone correction $(99.5 \%$ identity threshold for clonality).

y Tree species: $\mathrm{Pl}=$ lodgepole pine and $\mathrm{Pxj}=$ lodgepole $\times$ jack pine hybrids.

z Sampling done in 2005 (Dale et al. 2011); all other populations were sampled in 2012 to 2013. 
population structure analysis was inferred using a compositelikelihood approach implemented in dadi (Gutenkunst et al. 2009). The four lineages were named for the locations where the isolates were found; namely, Kispiox (most of the isolates included in this lineage were from populations of the Kispiox Valley region), AB (all the isolates of this lineage were from the Alberta region), $\mathrm{PG}$ (all isolates were from the Prince George region), and ABPG (isolates of this cluster were from the Alberta and Prince George region). Because $\partial \mathrm{a} \partial \mathrm{i}$ modeling is limited to three populations, we used the following sequential approach. We first assessed the history of the Kispiox lineage and the group of the three other lineages ( $\mathrm{AB}, \mathrm{PG}$, and $\mathrm{ABPG}$ ) and, second, the relationships and history within the AB/PG/ABPG group. In both cases, we adopted a nested-model approach by contrasting a model of strict isolation (SI) with a model assuming isolation and a rate of asymmetric migration $(\mathrm{m}=2 \mathrm{Ne}$ migrants/generation for a haploid species) between the time of their split and the present (isolation and migration [IM] model). Models assuming admixture between AB, PG, and ABPG were not tested because no clear evidence of admixture was detected between these three lineages (Supplementary Table S1).

The input data for $\partial \mathrm{a} \partial \mathrm{i}$ consisted of the SNPs detected in the GBS reads of the 119 D. septosporum isolates retained in the previous analyses (raw VCF generated after bcftools call). We first polarized the SNPs using Illumina reads generated for the $D$. pini isolate CBS 116487 mapped to the D. septosporum reference genome. Only biallelic SNPs with a quality value $>99.0$ and $<50 \%$ missing data in the ingroup sequences were retained. This resulted in a dataset of 11,141 biallelic SNPs (among which $12.1 \%$ were polarized with $D$. pini) for the history of Kispiox and the AB/PG/ ABPG group that were found among 966,350 callable nucleotide positions. For the three lineages within the AB/PG/ABPG group, we analyzed 809,375 callable nucleotide positions to obtain a dataset of 8,479 biallelic SNPs (among which 9.6\% were polarized with $D$. pini). To account for missing data, SNP datasets were projected down to 50 haploid individuals per lineage for modeling the history of Kispiox and the ABPG/AB/PG group and 15 haploid individuals per lineage for the modeling of the lineages within $\mathrm{AB} /$ PG/ABPG group.

Model parameters were fitted with the log optimization method. Searches began from 10 randomly perturbed starting positions, with 10,000 iterations, followed by five additional searches using bestinferred parameters from the previous step as a starting position with 1,000 iterations. Searches were executed in separate Python shells to prevent freezing of the optimization in bad parameter space. Improvement in likelihood (given the increase in model complexity) was determined by calculating the Akaike's information criterion (AIC) for each model (Akaike 1974). For the best-fit model, we estimated standard errors for parameters using the Godambe Information Matrix to reoptimize parameters for 100 bootstrap data sets consisting of SNPs randomly sampled with replacement from the original data set (Coffman et al. 2016).

Data accessibility and analyses reproducibility. SNP datasets and Python and $\mathrm{R}$ scripts are available at https:// github.com/feaunico/GBS_DSeptosporum.

\section{RESULTS}

GBS data processing. We assessed the genetic diversity of D. septosporum populations from western Canada by genotyping a total of 196 isolates (identified as D. septosporum using the ITS locus) (Feau et al. in press) from Alberta and two regions in British Columbia (Kispiox Valley and Prince George), generating 10,879 loci (including 1,491 biallelic SNPs) after filtering. Among those isolates, 13 genotypes failed and 64 clones were identified and removed, leaving 119 individuals from 16 populations (Table 1).

Diversity and population structure of $D$. septosporum in western Canada. The $\pi$ within regions ranged from 0.012 in the Kispiox Valley region to 0.021 in the Prince George region (Table 2, regions). Haplotype diversity was $1.3 \times$ higher in the Alberta region compared with the two regions from British Columbia (Kispiox Valley and Prince George) (Table 2, regions).

AMOVA indicated that most of the genetic variance was found between the three regions (Alberta, Kispiox Valley, and Prince George) (46.9\% of the total, $P<0.001$ ), and then within populations (45.3\% of the total; $P<0.01$ ) (Supplementary Table S2). Pairwise $F_{s t}$ estimates between populations reflected this structure, with significant values as high as 0.70 between populations from different regions (Table 3 ). $F_{s t}$ values between populations within Kispiox Valley and Alberta regions were very low (and for most of them nonsignificant), ranging from 0.0 to 0.02 in Alberta (mean $=$ $0.002 \pm 0.01)$ to 0.0 to 0.09 in Kispiox Valley $($ mean $=0.04 \pm 0.03)$. By contrast, there were large and significant $F_{s t}$ values among populations within the Prince George region, ranging from 0.19 to 0.48 (mean $=0.34 \pm 0.16)$, indicating a strong genetic structure within that region (Table 3). The Kenneth Creek (KC) population from the Prince George region displayed a unique pattern: the interregional pairwise $F_{s t}$ of this population was the lowest (average of $0.24 \pm 0.07$ [median value of 0.24 ] between $\mathrm{KC}$ and Kispiox Valley and $0.27 \pm 0.02$ [median $=0.26$ ] between $\mathrm{KC}$ and Alberta) (Table 2). These $F_{s t}$ values were significantly lower (Wilcoxon signed-rank test $P$ value $<0.05$ for each comparison) than the pairwise $F_{s t}$ values within the Prince George region (average of 0.34 \pm 0.15 ; median $=0.42$ ).

Genetic structure of $D$. septosporum populations from western Canada. The PCA revealed four clusters of samples in western Canada: the first three mostly correlated with geographic locations and a fourth was composed of a mixture of isolates from the Alberta and Prince George regions (Fig. 1A). To assess the level of admixture in each sample, we calculated the individual

TABLE 2. Genetic and haplotypic diversity in the regions of origin, genetic lineages, and full sample collection of Dothistroma septosporum identified in western Canada (clone-corrected sample of 119 isolates)

\begin{tabular}{lcccccc}
\hline Variables & $\begin{array}{c}\text { Sample } \\
\text { size }\end{array}$ & $\begin{array}{c}\text { Number of segregating } \\
\text { sites }\end{array}$ & $\begin{array}{c}\text { Nucleotide } \\
\text { diversity }\end{array}$ & $\begin{array}{c}\text { Tajima's } \\
\mathrm{D}\end{array}$ & $\begin{array}{c}\text { Average number of haplotypes } \\
(K)^{\mathrm{z}}\end{array}$ & $\begin{array}{c}\text { Haplotype diversity } \\
(\mathrm{He})^{\mathrm{z}}\end{array}$ \\
\hline $\begin{array}{l}\text { Regions } \\
\quad \text { Kispiox Valley }\end{array}$ & 58 & 710 & & & & \\
Prince George & 36 & 872 & 0.012 & -0.57 & $3.31( \pm 1.73) \mathrm{a}$ & $0.16( \pm 0.15) \mathrm{a}$ \\
$\quad$ Alberta & 25 & 655 & 0.021 & 0.43 & $2.96( \pm 1.57) \mathrm{b}$ & $0.16( \pm 0.17) \mathrm{a}$ \\
Lineages & & & 0.016 & -0.03 & $2.17( \pm 1.06) \mathrm{c}$ & $0.21( \pm 0.20) \mathrm{b}$ \\
$\quad$ Kispiox & 65 & 750 & 0.012 & -0.64 & $3.73( \pm 1.96) \mathrm{a}$ & $0.16( \pm 0.16) \mathrm{a}$ \\
AB & 19 & 290 & 0.008 & 0.18 & $2.01( \pm 0.97) \mathrm{b}$ & $0.13( \pm 0.13) \mathrm{b}$ \\
PG & 20 & 212 & 0.004 & -0.86 & $1.91( \pm 0.88) \mathrm{c}$ & $0.13( \pm 0.15) \mathrm{b}$ \\
ABPG & 15 & 420 & 0.011 & -0.80 & $1.56( \pm 0.74) \mathrm{d}$ & $0.11( \pm 0.16) \mathrm{c}$ \\
Full collection & 119 & 1,491 & 0.025 & -0.096 & $5.22( \pm 2.85)$ & $0.22(0.20)$ \\
\hline
\end{tabular}

y Estimated over an alignment length of 10,879 nucleotide sites.

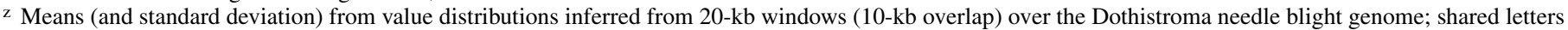
indicate means not significantly different $(P>0.05)$ according to a Tukey's honestly significant difference test. 
admixture coefficient with sNMF. Cross-entropy values showed a sharp decrease between $K=3$ and $K=5$ clusters (data not shown). At $K=2$ and $K=3$, isolates from the Kispiox Valley region formed a distinct and homogeneous cluster with little or no admixture (Fig. 1B). At higher $K$ values, populations of the Kispiox Valley region were still distinct yet with increasing levels of admixture (Fig. 1B). In contrast, isolates from the Prince George and Alberta regions showed a more heterogeneous pattern in accordance with the $F_{s t}$ results (Table 3 ). At all $K$ values, $55.5 \%$ of the samples from the Prince George region had $>80 \%$ of their loci assigned to one cluster (Fig. 1B and C, "grey" cluster). Another 25\% of the samples from the Prince George region had $>80 \%$ of their loci assigned to a second cluster shared with six samples from Alberta (Fig. 1B, "pink" cluster). A last cluster contained the $76 \%$ remaining samples from Alberta (Fig. 1B and C, "green" cluster). The remaining $19.4 \%$ of isolates from Prince George (seven isolates, including five from the $\mathrm{KC}$ population) showed a distinct pattern, with large proportions of their genome shared with isolates from the Kispiox Valley region (Fig. 1B and C, "orange" cluster).

The neighbor-joining tree based on Euclidean distances between all pairs of isolates showed similar clustering patterns, clearly highlighting the separation between the orange cluster of isolates from the Kispiox Valley region and the seven Prince George isolates previously mentioned with the Alberta and other Prince George isolates (Fig. 1B). The orange cluster was renamed "Kispiox lineage" because most of the isolates included in it were from the populations collected in the Kispiox Valley region. The cluster formed by the majority of Prince George and Alberta isolates was subdivided in three statistically supported lineages $(B S=100 \%)$, each corresponding to the groups identified in the PCA and structure analyses at $K=4$ and 5 . This included a green cluster $=\mathrm{AB}$ lineage, because all the isolates of this cluster were from the Alberta region; a grey cluster $=$ PG lineage, with isolates exclusively from the Prince George region; and a pink cluster $=$ ABPG lineage, which includes six isolates from the Alberta region and nine isolates from the Prince George region (Fig. 1B and C). No specific association was observed between one of these lineages and the host species from which they were isolated. The two lineages identified in the Alberta populations (AB and ABPG) were randomly found on the two host species sampled in this region, $P$. contorta var. latifolia or $P$ contorta $\times$ P. banksiana (Table 1$)$.
Genealogy of DNB isolates from Canada. We determined whether the clusters observed at $K=4$ corresponded to distinct and new independent lineages or to subdivisions within $D$. septosporum lineages previously characterized by inferring maximumlikelihood and maximum-parsimony genealogy with 119 Canadian isolates of D. septosporum and 18 D. septosporum isolates collected on five continents (Bradshaw et al. 2019). The genealogy supported the resolution of three monophyletic groups, including two wellsupported groups (BS $\geq 83 \%$ in maximum likelihood and $\mathrm{BS}=$ $100 \%$ in maximum parsimony) corresponding to the Kispiox lineage and the group of three lineages AB, PG, and ABPG (Fig. 2). This second group could be further subdivided into three monophyletic groups (each with $100 \%$ BS in maximum parsimony and maximum likelihood) matching the three individual clusters identified at $K=4$ in the population structure analysis (i.e., ABPG, AB, and $\mathrm{PG}$ lineages). The third group corresponded to the most basal divergence and included all non-American D. septosporum individuals. The two North American isolates previously characterized and added to our analysis (one from Canada [CAN3] and one from the United States [USA12]) (Bradshaw et al. 2019), clustered with the $\mathrm{AB} / \mathrm{PG} / \mathrm{ABPG}$ group. However, both isolates remained in an independent position apart from these three lineages, suggesting the existence of additional isolated clusters of isolates within this group.

Genetic and haplotypic diversity in the four $D$. septosporum lineages. We assessed and compared values of $\pi$, Tajima's D, and haplotypic diversity in each of the four lineages in the western Canadian populations. The $\pi$ varied from 0.004 in PG to 0.012 in the Kispiox lineage (Table 2, lineages). Tajima's D values for the Kispiox, PG, and ABPG lineages were negative, suggesting excesses of rare variants; this value was positive for the $\mathrm{AB}$ lineage and was closer to the null value expected under demographic equilibrium. Finally, the Kispiox lineage had a significantly higher number of haplotypes per $20 \mathrm{~kb}$ windows $(3.73 \pm 1.96)$ and haplotype diversity $(0.16 \pm 0.16)$ than the three other lineages (Table 2, lineages).

Extent of sexual recombination and random mating within D. septosporum lineages. The hypothesis that D. septosporum lineages undergo regular cycles of sexual reproduction was tested by studying the frequencies and distributions of the two mating types. In all, 112 isolates were genotyped at the mating-type locus, resulting in 51 isolates containing the Mat1-1 idiomorph and 61

TABLE 3. Genetic differentiation between pairwise Dothistroma septosporum populations ${ }^{\mathrm{z}}$

\begin{tabular}{|c|c|c|c|c|c|c|c|c|c|c|c|c|c|c|c|c|}
\hline \multirow[b]{2}{*}{ Population } & \multicolumn{5}{|c|}{ Alberta } & \multicolumn{3}{|c|}{ Prince George } & \multicolumn{8}{|c|}{ Kispiox Valley } \\
\hline & ABTIC & BRCB & CLG & EM\&Mt & WCM/WMt & $\mathrm{KC}$ & PGTIS & WC & BUC & KLD & $\mathrm{KSC}$ & NY & SD2 & $\mathrm{SM}$ & SUN & UNBC \\
\hline \multicolumn{17}{|l|}{ Alberta } \\
\hline ABTIC & $\ldots$ & - & - & - & - & - & $*$ & $* *$ & $*$ & - & $*$ & $*$ & - & $* * *$ & $* *$ & $*$ \\
\hline BRCB & -0.10 & $\ldots$ & - & - & - & $* *$ & $* * *$ & $* *$ & $* *$ & $* * *$ & $* * *$ & $* * *$ & $* * *$ & $* * *$ & $* * *$ & $* * *$ \\
\hline CLG & -0.19 & -0.05 & $\ldots$ & - & - & $*$ & $*$ & $* *$ & $*$ & $*$ & $*$ & $* * *$ & * & $* * *$ & $* * *$ & $* *$ \\
\hline EM\&Mt & -0.09 & -0.03 & -0.01 & $\ldots$ & - & $* * *$ & $* * *$ & $* * *$ & $* * *$ & $*$ & $*$ & $* *$ & $*$ & $* * *$ & $* * *$ & $*$ \\
\hline WCM/WMt & -0.05 & -0.09 & -0.04 & 0.02 & $\ldots$ & $* * *$ & $* *$ & $* * *$ & $* * *$ & $* * *$ & $* * *$ & $* * *$ & $* * *$ & $* * *$ & $* * *$ & $* * *$ \\
\hline \multicolumn{17}{|l|}{ Prince George } \\
\hline $\mathrm{KC}$ & 0.25 & 0.26 & 0.26 & 0.31 & 0.26 & $\ldots$ & $*$ & $* * *$ & $*$ & $*$ & $* *$ & $* * *$ & $* * *$ & $* * *$ & $* * *$ & - \\
\hline PGTIS & 0.35 & 0.3 & 0.36 & 0.38 & 0.30 & 0.19 & $\ldots$ & $* * *$ & $* * *$ & $* * *$ & $* * *$ & $* * *$ & $* * *$ & $* * *$ & $* * *$ & $* * *$ \\
\hline WC & 0.47 & 0.28 & 0.39 & 0.5 & 0.24 & 0.36 & 0.48 & $\ldots$ & $* * *$ & $* *$ & $* * *$ & $* * *$ & $* * *$ & $* * *$ & $* * *$ & $* * *$ \\
\hline \multicolumn{17}{|l|}{ Kispiox Valley } \\
\hline BUC & 0.68 & 0.57 & 0.6 & 0.69 & 0.55 & 0.24 & 0.65 & 0.57 & $\ldots$ & - & - & - & - & - & $* * *$ & - \\
\hline KLD & 0.66 & 0.54 & 0.56 & 0.68 & 0.52 & 0.22 & 0.64 & 0.55 & 0 & $\ldots$ & - & - & - & - & $* * *$ & - \\
\hline $\mathrm{KSC}$ & 0.69 & 0.57 & 0.59 & 0.7 & 0.55 & 0.24 & 0.66 & 0.58 & 0.02 & 0.02 & $\ldots$ & - & - & $*$ & $*$ & - \\
\hline NY & 0.68 & 0.58 & 0.6 & 0.69 & 0.56 & 0.27 & 0.65 & 0.58 & 0.03 & 0.02 & 0.04 & $\ldots$ & - & $*$ & $* * *$ & - \\
\hline SD2 & 0.69 & 0.57 & 0.6 & 0.70 & 0.55 & 0.24 & 0.65 & 0.58 & 0.03 & -0.04 & 0.08 & 0.06 & $\ldots$ & $*$ & $*$ & - \\
\hline SM & 0.70 & 0.62 & 0.64 & 0.70 & 0.61 & 0.3 & 0.66 & 0.61 & -0.05 & 0.09 & 0.06 & 0.06 & 0.07 & $\ldots$ & $* *$ & $*$ \\
\hline SUN & 0.70 & 0.62 & 0.64 & 0.70 & 0.60 & 0.31 & 0.66 & 0.61 & 0.07 & 0.07 & 0.07 & 0.06 & 0.09 & 0.06 & $\ldots$ & - \\
\hline UNBC & 0.47 & 0.43 & 0.43 & 0.52 & 0.42 & 0.09 & 0.5 & 0.47 & 0 & -0.03 & 0.01 & 0.04 & 0.01 & 0.06 & 0.03 & $\ldots$ \\
\hline
\end{tabular}

$\mathrm{z}$ Bottom triangle $=$ fixation index $\left(F_{s t}\right)$ values and top triangle $=F_{s t} P$ values estimated from 1,000 permutations of haplotypes between populations. - indicates not significant and $*, * *$, and $* * *$ indicate $P \leq 0.05,0.01$, and 0.001 , respectively. $F_{s t}$ values were obtained with the clone corrected-sample of 119 D. septosporum isolates. 
isolates with the Mat1-2 idiomorph. Those numbers were reduced after clone correction to 67 isolates, with 24 Mat1-1 idiomorph and 43 Mat1-2 idiomorphs (Table 4). Distribution of the matingtype idiomorphs in the Kispiox lineage and in each of the three other lineages was not significantly different from a 1:1 ratio of random mating, a pattern consistent with contemporary sexual reproduction. However, the two idiomorphs differed in frequency after clone correction for the AB and PG lineages, likely because of the low number of isolates genotyped (Table 4). Differences in linkage disequilibrium were observed between the Kispiox and the three other lineages. Linkage disequilibrium decayed two times faster for the Kispiox lineage (reaching $50 \%$ of maximum linkage disequilibrium within $3.1 \mathrm{~kb}$ ) than for the PG lineage (6.3 kb) (Fig. 3A). Linkage disequilibrium in AB and ABPG decayed even more slowly, suggesting a stronger association between alleles within these two lineages (Fig. 3A). In addition, distribution of standardized index of association values $\left(\bar{r}_{d}\right)$ among D. septosporum scaffolds support evidence for sexual
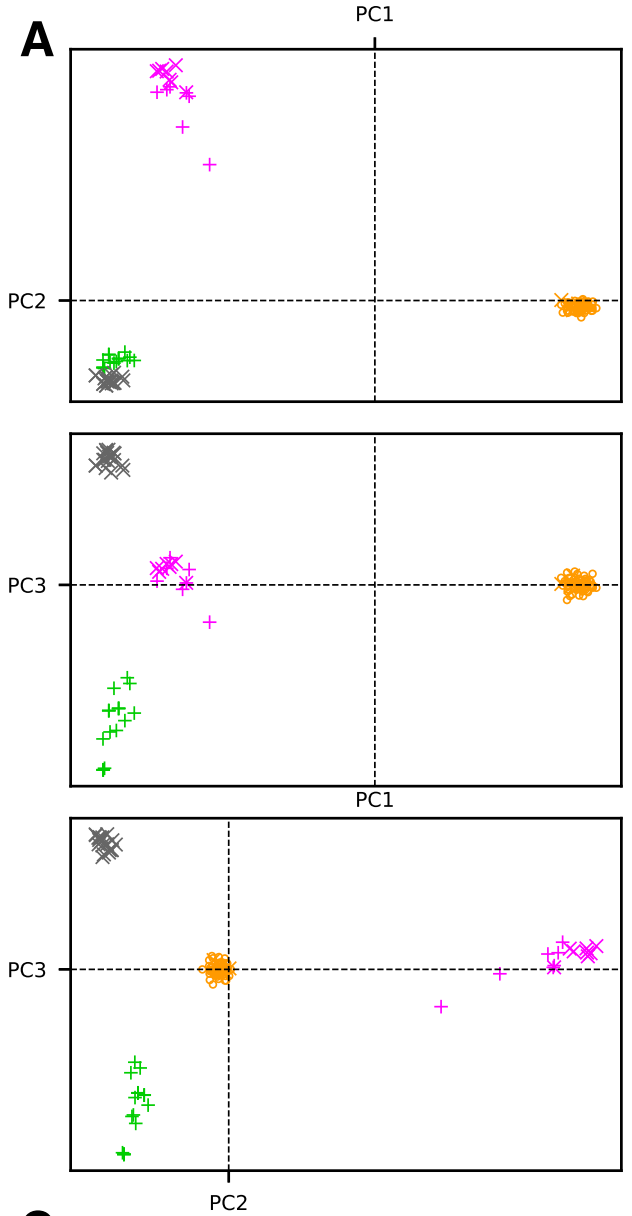

C

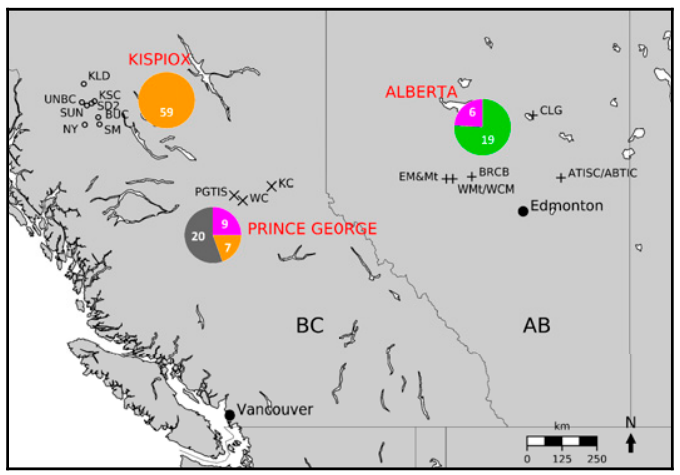

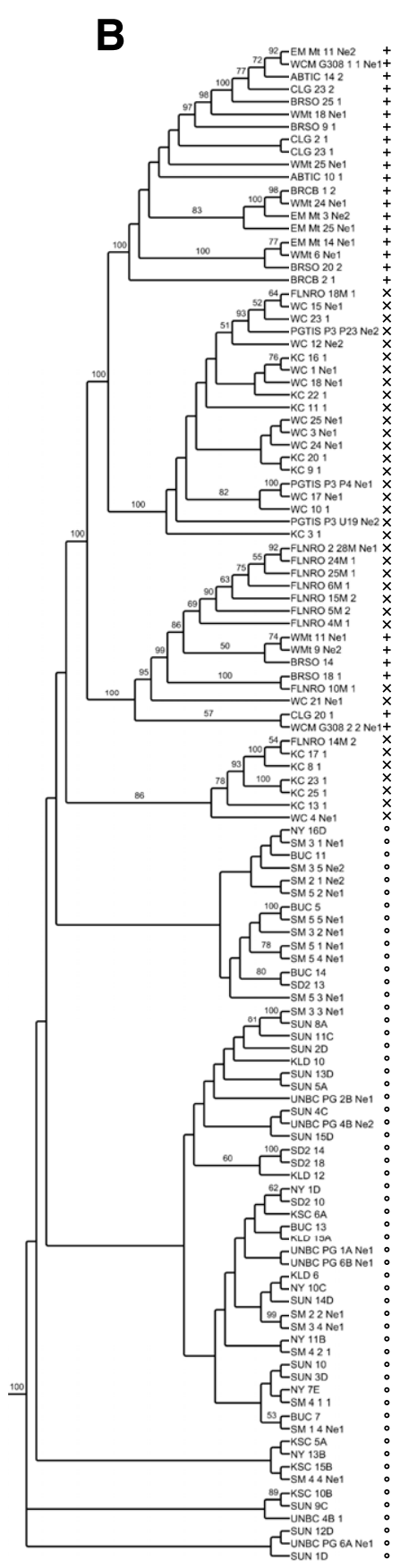
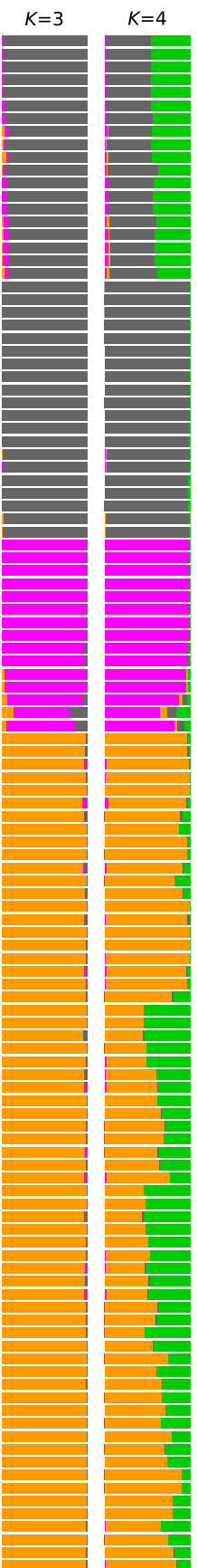

$A B$

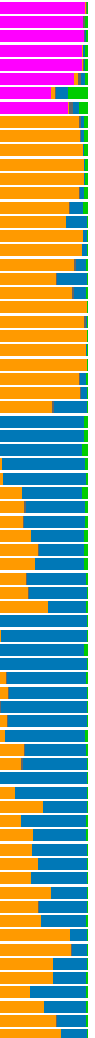

ABPG

\section{PG}
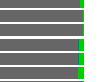
포

Kispiox

Fig. 1. Genetic structure of the western Canadian population of Dothistroma septosporum. A, Principal component (PC) analysis based on 1,491 biallelic singlenucleotide polymorphisms. Isolates belonging to the four Dothistroma needle blight (DNB) lineages identified in this study are indicated with colors: orange $=$ Kispiox, green $=\mathrm{AB}$, gray $=\mathrm{PG}$, and pink $=\mathrm{ABPG}$. Geographic origin of the isolates is indicated with symbols: $+=$ Alberta region, $\mathrm{x}=$ Prince George region, and $\mathrm{o}=$ Kispiox Valley region. B, Left: Neighbor-joining tree based on pairwise Euclidean distance between DNB isolates; number above nodes are bootstrap values inferred from 1,000 bootstrap replicates. Right: sNMF clusters for $K=2$ to $K=5$, corresponding to the isolates presented in the neighbor-joining tree. Lineage and geographic origins are indicated with the same colors and symbols as those displayed in panel A. C, Distribution of the four DNB lineages among three regions in Western Canada. Populations sampled in these regions are represented with the following symbols: $+=$ Alberta region, $\mathrm{x}=$ Prince George region, and $\mathrm{o}=\mathrm{Kispiox}$ Valley region. The proportion and number of isolates for each lineage are represented in the pie charts with the same colors as those displayed in panels A and B. 
recombination and random mating in the Kispiox lineage, while higher $\bar{r}_{d}$ values in AB, PG, and ABPG indicated nonrandom mating within these lineages (Fig. 3B).

Demographic history of DNB lineages. We used a composite-likelihood approach to infer the past evolutionary history of the Kispiox lineage and the $\mathrm{AB} / \mathrm{PG} / \mathrm{ABPG}$ group and of the three lineages within the AB/PG/ABPG group. In both cases, we found more support for the isolation with the IM model than with the less parameterized SI model (Supplementary Table S3). Assuming an average rate of 1.0E-09 mutation/site/generation in ascomycetes (Kasuga et al. 2002; Zhu et al. 2014), one sexual generation per year, and a genome subsample size of 966,350

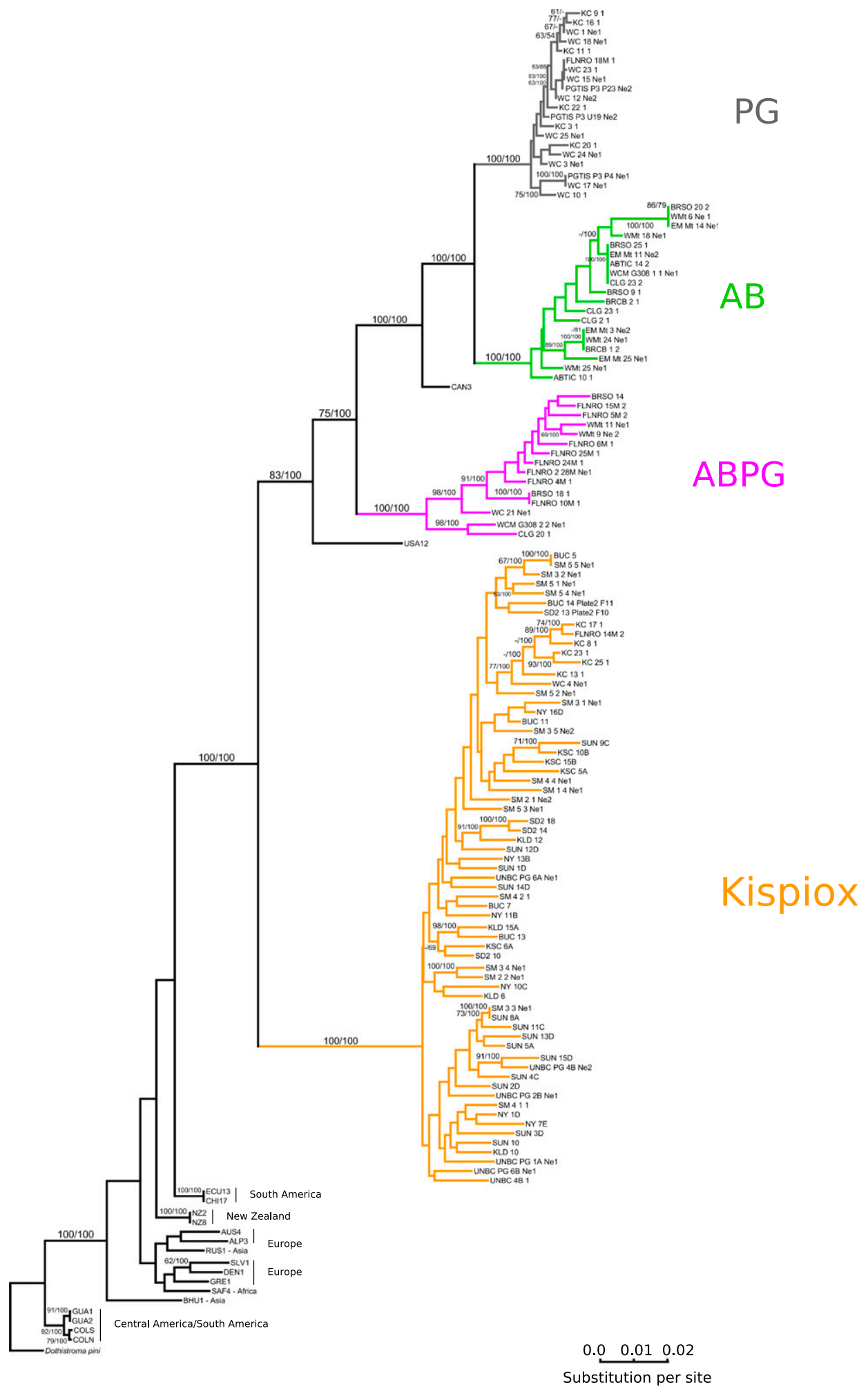

Fig. 2. Phylogenetic relationships among western Canadian isolates of Dothistroma septosporum. Maximum-likelihood (RAxML) phylogenetic tree inferred from 1,348 single-nucleotide polymorphisms; numbers above nodes are bootstrap values inferred from 100 bootstrap replicates under maximum parsimony (left value) and maximum likelihood (right). Four Dothistroma needle blight lineages identified in this study are indicated with colors: orange $=$ Kispiox, green $=\mathrm{AB}$, gray $=$ $\mathrm{PG}$, and pink = ABPG. 
callable nucleotide positions, the best model for Kispiox and the AB/PG/ABPG group inferred a split 31,433 years before present (ybp) ( $\pm 95 \%$ confidence interval [CI]: 45,508 to 17,359$)$ between the two lineages (Fig. 4A). Among the three possible models for standard isolation within the $\mathrm{AB} / \mathrm{PG} / \mathrm{ABPG}$ group, the most likely suggested an early split between the ABPG lineage and a common ancestor to the $\mathrm{PG}$ and $\mathrm{AB}$ lineages, followed by a more recent split between these two last lineages $(-\mathrm{Ln}=1,380.85$; $\mathrm{AIC}=2,751.7)$ (Supplementary Table S4). Adding contemporaneous asymmetric migration between each pair of lineages significantly improved this model ( $\mathrm{Ln}=-1,104.63 ;$ AIC = 2,231.2) (Supplementary Table S4). Assuming the same mutation rate as above and 809,375 callable nucleotide position, this model infers a first split between ABPG and the common ancestor to the two other lineages $9,812 \mathrm{ybp}( \pm 95 \%$ CI: 13,808 to 5,817 ) and a split between AB and PG 7,212 ybp ( $\pm 95 \%$ CI: 10,910 to 3,515$)$. According to the same model, the migration rates between the $\mathrm{AB}$ and $\mathrm{ABPG}$ lineages $(0.21$ individuals in $\mathrm{ABPG}$ would be from $\mathrm{AB}$ each generation and 0.1 in the other direction) would be $7 \times(0.03$ individuals from $\mathrm{PG}$ would be from $\mathrm{AB}$ each generation) to $500 \times$ (1E-04 individuals from $\mathrm{AB}$ would be from PG each generation) higher than any other exchanges, suggesting strong gene flow between the lineage shared between the Prince George and Alberta region (ABPG) and the lineage exclusive to the Alberta region (AB) (Fig. 4B).

\section{DISCUSSION}

The western Canadian population of $D$. septosporum is subdivided in four genetic lineages. Our study of 16 populations (119 isolates after clone correction) of D. septosporum from the Canadian provinces of Alberta and British Columbia has revealed the existence of a very clear genetic structure, with four main clusters. A genome-based genealogy confirmed the resolution of these 119 isolates into four independent clusters, distinct from DNB individuals collected outside of North America. Based on these findings, we defined these clusters as new distinct lineages undergoing genetic isolation. There are many examples in fungal plant pathogens of geographically widespread genetic lineages with the potential for adapting rapidly to environmental changes (Gladieux et al. 2015, 2018). Using microsatellite markers, Barnes et al. (2014) identified a strong genetic structure correlated with geography among a worldwide collection of 458 isolates of D. septosporum from 14 countries on six continents. Three distinct clonal lineages were identified in the Southern Hemisphere, each corresponding to different introduction events of the pathogen concomitant to the extensive development of commercial plantations of $P$. radiata (Barnes et al. 2014; Bradshaw et al. 2019). At a smaller geographic scale, three isolated genetic lineages were identified in Scotland, including one indigenous lineage on native Scots pine (P. sylvestris) and two believed to have been introduced

TABLE 4 . The $\chi^{2}$ values for the distribution of mating-type idiomorphs in the lineages of Dothistroma septosporum identified in western Canada

\begin{tabular}{lrrl}
\hline Lineage & Mat1.1 & Mat1.2 & Deviation from $1: 1$ \\
\hline All genotyped samples & & & \\
$\quad$ Kispiox & 18 & 24 & $\chi^{2}=0.86, P=0.35$ \\
AB & 6 & 14 & $\chi^{2}=3.2, P=0.07$ \\
PG & 9 & 12 & $\chi^{2}=0.42, P=0.51$ \\
ABPG & 18 & 11 & $\chi^{2}=1.70, P=0.19$ \\
All & 51 & 61 & $\chi^{2}=0.89, P=0.34$ \\
Clone-corrected samples & & & \\
$\quad$ Kispiox & 14 & 22 & $\chi^{2}=1.77, P=0.18$ \\
AB & 2 & 6 & $\chi^{2}=2.0, P=0.18$ \\
PG & 4 & 11 & $\chi^{2}=3.26, P=0.07$ \\
ABPG & 4 & 4 & $\ldots$ \\
All & 24 & 43 & $\chi^{2}=5.38, P<0.05$ \\
\hline
\end{tabular}

with exotic pine species from continental Europe and North America (Ennos et al. 2020; Piotrowska et al. 2017).

The exact origin and drivers for the differentiation process of the four lineages identified in western Canada remains uncertain. However, the presence of both mating-type idiomorphs in balanced frequency in each of these lineages, their high level of haplotypic diversity compared with recently founded populations (e.g., those introduced with $P$. radiata in the South Hemisphere; Barnes et al. 2014), as well as the absence of any direct phylogenetic relationships with non-Canadian isolates suggest that they were not recently introduced from an exotic source into western Canada. Alternatively, these lineages could have been derived as a result of the isolation of lodgepole pine populations during the last glacial period. Expanding populations that are derived from populations existing in refuges during periods of glaciations are usually characterized by higher genetic diversity and an excess of rare variants in comparison with those that have been more recently founded (Sakalidis et al. 2016; Vercken et al. 2010). Because of the
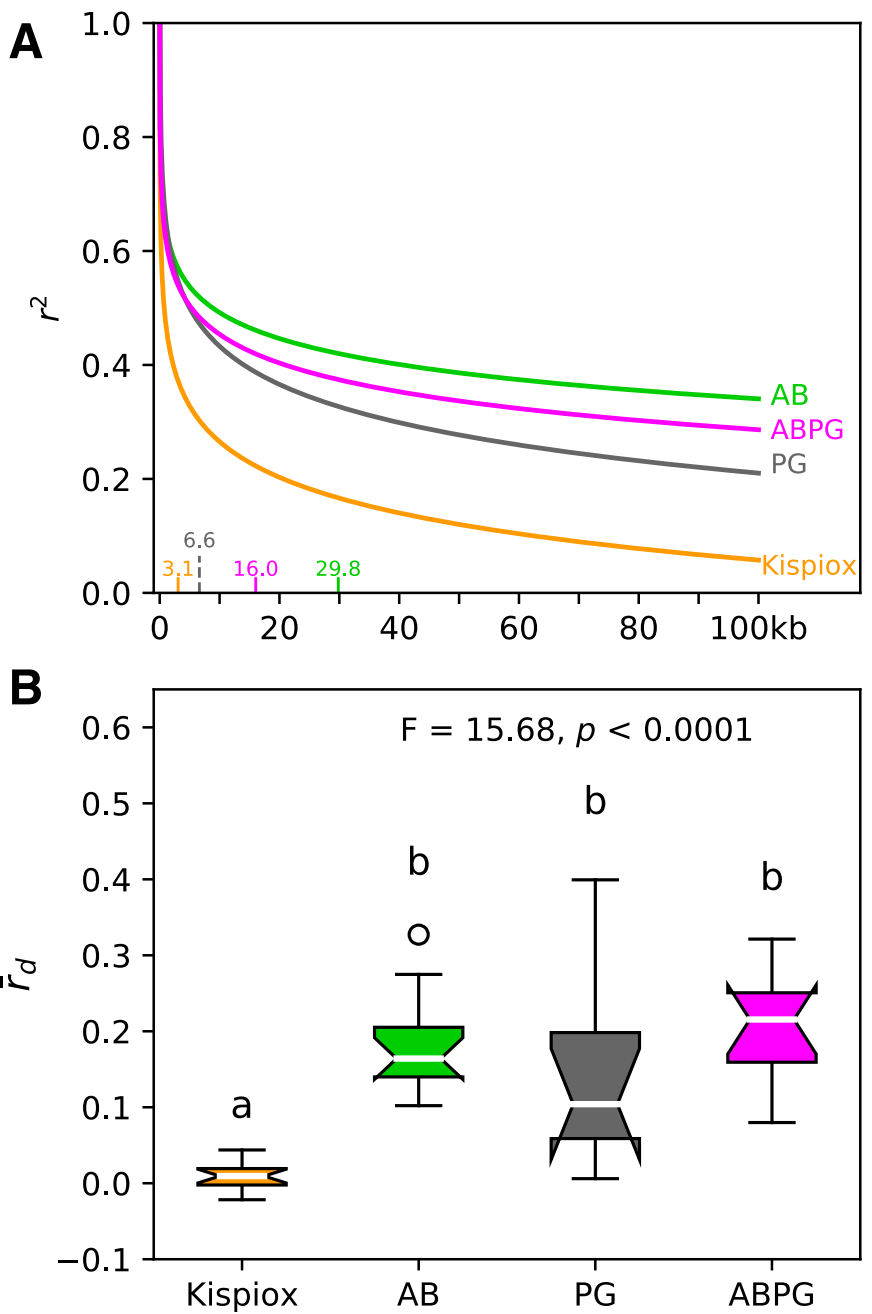

Fig. 3. Extent of sexual recombination and random mating in the four Dothistroma septosporum lineages (Kispiox, AB, PG, and ABPG) identified in western Canada. A, Decay of linkage-disequilibrium $\left(r^{2}\right)$; values on the $\mathrm{X}$-axis represent the physical distance at which half of the total linkage was lost for each lineage. B, Distributions of the normalized index of association $\left(\bar{r}_{d}\right)$ calculated among 17 scaffolds of D. septosporum; distribution means sharing a letter are not significantly different $(P>0.05)$ according to a Tukey's honest significant difference test. The four Dothistroma needle blight lineages identified in this study are indicated with colors: orange $=$ Kispiox, green $=A B$, gray $=\mathrm{PG}$, and pink $=\mathrm{ABPG}$. 
complex heterogeneity of its geography, the Pacific Northwest hosted multiple isolated glacial refugia. Godbout et al. (2008) identified four differentiated lodgepole pine genetic groups representative of the glacial refugia located to the southeast of the Cascade and Rocky Mountains and on the Pacific coast. We estimated that the divergence between the lineage found in Kispiox Valley region and in one population near Prince George (constituting the Kispiox lineage) and the three other lineages (AB, PG, and ABPG) happened 45,508 to 17,359 ybp, coinciding with the last glacial maximum (i.e., 21,000 ybp) (Mix et al. 2001; Shaw et al. 2006) and the beginning of the ice retreat that started 17,000 ybp (Mix et al. 2001; Ward et al. 2003). The origin of the three other lineages (PG, $\mathrm{AB}$, and $\mathrm{ABPG}$ ) is more recent, with estimates within the range of 13,808 to $3,515 \mathrm{ybp}$, corresponding to the period of recolonization following the last glaciation, before lodgepole pine reached its near present-day northern limit (MacDonald and Cwynar 1985).

The last DNB epidemics in British Columbia originated from a genetically diverse and expanding population. Patterns of genetic diversity found in the unique lineage of the Kispiox Valley region (Kispiox lineage) are quite distinct from the three other lineages. This lineage has the highest $\pi$ of all four lineages. However, the average Tajima's D is negative, indicating recent population expansion. The Kispiox lineage also has a higher haplotypic diversity and a lower level of linkage disequilibrium, suggesting random mating and possibly a lower contribution of the asexual stage. The presence of both mating types in similar proportions as well as multilocus genetic analyses with anonymous dominant markers suggested that the populations composing this lineage were undergoing random mating through a substantial amount of sexual reproduction (Dale et al. 2011; Groenewald et al. 2007). These populations were sampled from natural stands and managed plantations of lodgepole pine in which an unprecedented DNB outbreak was believed to be caused by changing climate conditions (Woods et al. 2005). Assuming that the last outbreak in this area was caused by individuals of this lineage, the buildup of a successful epidemic population was likely favored by the presence of a local population with a high potential for sexual reproduction (and subsequent haplotypic diversity) in native lodgepole pine stands. Whether or not this lineage possesses distinct adaptive traits remains to be determined.

Pine cultivation influenced genetic diversity of Prince George and Alberta D. septosporum populations. Dendrochronology studies and disease reports both support the hypothesis that D. septosporum has been present for several decades on lodgepole pine in north-central and northeastern British Columbia (Dale et al. 2011; Drenkhan et al. 2016; Watt et al. 2009; Welsh et al. 2009). The presence of D. septosporum in Alberta has only recently been noticed (Feau et al. in press). However, a more ancient presence of this species in the natural distribution range of lodgepole pine in northwestern Alberta is suspected but remains uncertain due to the confusion with the sister (and morphologically similar) species D. pini (Feau et al. in press). Interestingly, the AB lineage, exclusively found in Alberta, showed a high haplotype diversity and characteristics of a population under demographic equilibrium, thus supporting the idea of an ancient presence of
A

\section{Divergence between Kispiox lineage and $A B / P G / A B P G$ group}

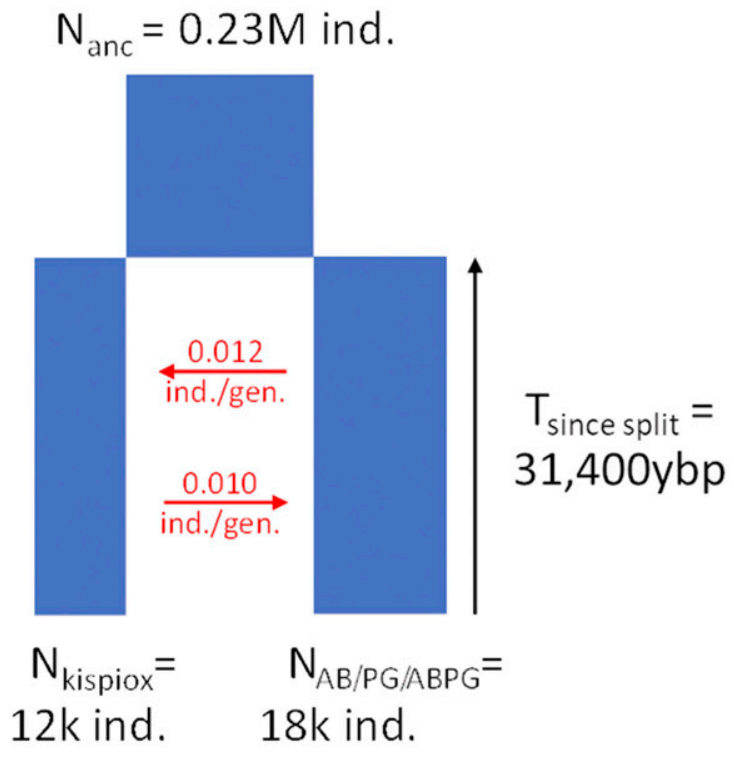

B

\section{Divergence between $A B, P G$ and $A B P G$ lineages}

$$
\mathrm{N}_{\mathrm{anc}}=0.26 \mathrm{M} \text { ind }
$$

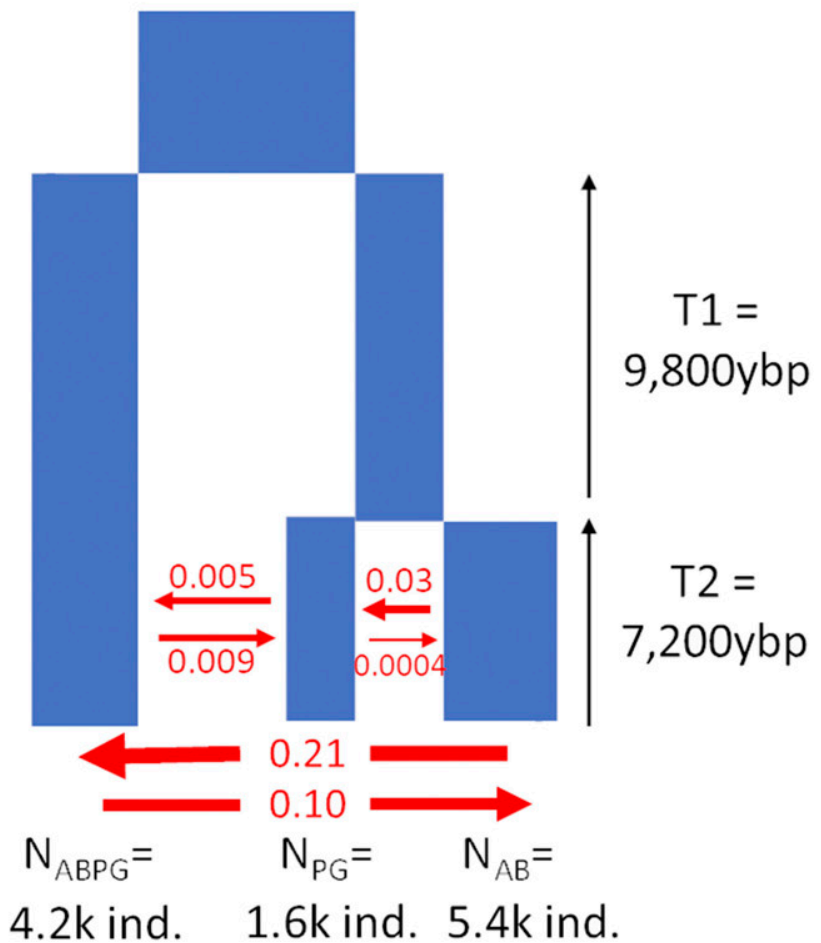

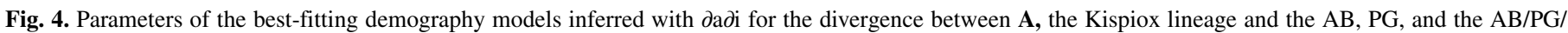

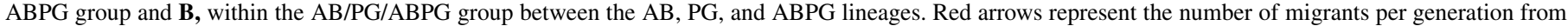
one lineage to another one. 
D. septosporum in this area. In contrast, the PG lineage, exclusively found in the Prince George region, and the ABPG lineage, shared between the Prince George and Alberta regions, have genetic characteristics of populations drifting from demographic equilibrium, with a pronounced excess of rare alleles and deviation from random mating.

The Prince George area has been one of the central places in British Columbia for lodgepole pine breeding and nursery production for reforestation since the 1970s (Government of British Columbia). The development of improved lodgepole pine genetic resources in the last decades resulted in intensive exchange of genetic material between seed planning zones (SPZs) in this area and SPZs several degrees of latitude to the south (Ukrainetz et al. 2018). The majority of the D. septosporum populations sampled in the Prince George and Alberta regions were from plantations established to test geographic provenances, clone banks, and seed orchards planted with local and nonlocal lodgepole pine provenances and lodgepole $\times$ jack pine hybrids (P. contorta var. latifolia $\times$ $P$. banksiana Lamb.). The intensive efforts spent in pine breeding and cultivation and the subsequent exchanges of genetic material have probably played a role in mixing DNB populations and modifying the genetic structure of the DNB lineages that were naturally infecting native lodgepole pine in this area. Three lineages (out of the four described in this study) compose the DNB populations sampled in this area, likely reflecting host diversity and movement history. The lodgepole pine breeding program in Alberta is more recent but has involved transfer of improved genetic material from the Prince George area (MacLachlan et al. 2017) and population provenances from different areas among the natural range of $P$. contorta in British Columbia and Alberta.

Practically, for both tree improvement programs (i.e., British Columbia and Alberta), lodgepole pine scions are collected from genotypes selected in wild stands (in different, often warmer locations than the sites where they will be deployed) and grafted in a nursery on local rootstock before being transferred in seed orchards or clone banks, resulting in a substantial risk of spreading the pathogen from natural pine stands and nurseries to other managed stands (A. Benowicz, personal communication). Modeling of the demographic history of the three main lineages found in these two areas support this hypothesis, because the best model inferred indicated a stronger contemporary migration from the lineage found exclusive to the Alberta region $(\mathrm{AB})$ and the lineage shared between the Prince George region and the Alberta region (ABPG). This connectivity indicates high rates of gene flow between genetic lineages (an incomplete genetic isolation) and could indicate a high degree of recent (rapid) movement of this tree pathogen across this geographical area. Given the limited dispersal of the pathogen at large geographical scales (Boateng and Lewis 2015; Dale et al. 2011; Mullett et al. 2016) human-mediated transport is the most likely mechanism of dispersal in this case, similar to that of other tree pathogens (Herath et al. 2016; Sakalidis et al. 2016; Tabima et al. 2020).

Climate change is affecting forest health, compounding biotic and abiotic stresses (Dale et al. 2001; Pautasso et al. 2015; Trumbore et al. 2015). Current breeding efforts incorporate assisted gene flow to CBST policies to match reforestation seedlots with future climates (MacLachlan et al. 2017). Our findings suggest that increased movement of tree planting material could have some major epidemiological consequences by facilitating connectivity, hybridization, or admixture between DNB lineages in the process of genetic isolation. Because D. septosporum is hypothesized to have a hemibiotrophic lifestyle (Kabir et al. 2015), it is possible that asymptomatic but infected pine material was moved in the past. Indeed, this example highlights the potential risks of unknowingly moving asymptomatic pathogen-infected material during assisted migration activities. Such secondary contact could lead to the emergence of new genotypes, enhancing the risk to native lodgepole and jack pine trees in British Columbia and Alberta. This was observed when exotic $P$. nigra was planted in the United Kingdom (Britain). A new epidemic DNB lineage was introduced with $P$. nigra trees and hybridized with the local endemic lineage, increasing the risk on native Scot pine (Ennos et al. 2020; Piotrowska et al. 2017). Knowledge of DNB population structure is important to ensure monitoring of the pathogen and to assess the susceptibility of the newly deployed pine genotypes to the lineages described here. We expect that genome sequencing of a more comprehensive collection of DNB isolates will help elucidate relationships between Canadian lineages and other populations and lineages found around the world. Phenotypic characterization of those lineages, including their virulence against the deployed host genotypes, will be essential to mitigate future outbreaks of DNB.

\section{ACKNOWLEDGMENTS}

We thank P. Herath, W. Vasquez, and W. Ho for technical assistance with fungal isolations.

\section{LITERATURE CITED}

Agapow, P.-M., and Burt, A. 2001. Indices of multilocus linkage disequilibrium. Mol. Ecol. Notes 1:101-102.

Akaike, H. 1974. A new look at the statistical model identification. IEEE Trans. Automat. Contr. 19:716-723.

Andrews, S. 2010. Fast QC: A quality control tool for high throughput sequence data. Babraham Bioinformatics. http://www.bioinformatics.babraham. ac.uk/projects/fastqc/

Barnes, I., Wingfield, M. J., Carbone, I., Kirisits, T., and Wingfield, B. D. 2014. Population structure and diversity of an invasive pine needle pathogen reflects anthropogenic activity. Ecol. Evol. 4:3642-3661.

Boateng, K., and Lewis, K. J. 2015. Spore dispersal by Dothistroma septosporum in northwest British Columbia. Phytopathology 105:69-79.

Bolger, A. M., Lohse, M., and Usadel, B. 2014. Trimmomatic: A flexible trimmer for Illumina sequence data. Bioinformatics 30:2114-2120.

Boroń, P., Lenart-Boroń, A., Mullett, M., Kraj, W., Grad, B., and Kowalski, T. 2019. Temporal changes in the population structure of Dothistroma septosporum at the site of the first recorded outbreak in Poland. Plant Pathol. 68: 383-391.

Bradshaw, R. E., Ganley, R. J., Jones, W. T., and Dyer, P. S. 2000. High levels of dothistromin toxin produced by the forest pathogen Dothistroma pini. Mycol. Res. 104:325-332.

Bradshaw, R. E., Sim, A. D., Chettri, P., Dupont, P.-Y., Guo, Y., Hunziker, L., McDougal, R. L., Van der Nest, A., Fourie, A., Wheeler, D., Cox, M. P., and Barnes, I. 2019. Global population genomics of the forest pathogen Dothistroma septosporum reveal chromosome duplications in high dothistromin-producing strains. Mol. Plant Pathol. 20:784-799.

Coffman, A. J., Hsieh, P. H., Gravel, S., and Gutenkunst, R. N. 2016. Computationally efficient composite likelihood statistics for demographic inference. Mol. Biol. Evol. 33:591-593.

Dale, A. L., Lewis, K. J., and Murray, B. W. 2011. Sexual reproduction and gene flow in the pine pathogen Dothistroma septosporum in British Columbia. Phytopathology 101:68-76.

Dale, V. H., Joyce, L. A., McNulty, S., Neilson, R. P., Ayres, M. P., Flannigan, M. D., Hanson, P. J., Irland, L. C., Lugo, A. E., Peterson, C. J., Simberloff, D., Swanson, F. J., Stocks, B. J., and Wotton, M. 2001. Climate change and forest disturbances. Bioscience 51:723.

Danecek, P., Auton, A., Abecasis, G., Albers, C. A., Banks, E., DePristo, M. A., Handsaker, R. E., Lunter, G., Marth, G. T., Sherry, S. T., McVean, G., Durbin, R., and 1000 Genomes Project Analysis Group. 2011. The variant call format and VCFtools. Bioinformatics 27:2156-2158.

de Wit, P. J. G. M., van der Burgt, A., Ökmen, B., Stergiopoulos, I., Abd-Elsalam, K. A., Aerts, A. L., Bahkali, A. H., Beenen, H. G., Chettri, P., Cox, M. P., Datema, E., de Vries, R. P., Dhillon, B., Ganley, A. R., Griffiths, S. A., Guo, Y., Hamelin, R. C., Henrissat, B., Kabir, M. S., Jashni, M. K., Kema, G., Klaubauf, S., Lapidus, A., Levasseur, A., Lindquist, E., Mehrabi, R., Ohm, R. A., Owen, T. J., Salamov, A., Schwelm, A., Schijlen, E., Sun, H., van den Burg, H. A., van Ham, R. C. H. J., Zhang, S., Goodwin, S. B., Grigoriev, I. V., Collemare, J., and Bradshaw, R. E. 2015. Correction: The genomes of the fungal plant pathogens Cladosporium fulvum and Dothistroma septosporum reveal adaptation to different hosts and lifestyles but also signatures of common ancestry. PLoS Genet. 11:e1005775.

Drenkhan, R., Tomešová-Haataja, V., Fraser, S., Bradshaw, R. E., Vahalík, P., Mullett, M. S., Martín-García, J., Bulman, L. S., Wingfield, M. J., Kirisits, T., Cech, T. L., Schmitz, S., Baden, R., Tubby, K., Brown, A., Georgieva, M., Woods, A., Ahumada, R., Jankovský, L., Thomsen, I. M., Adamson, K., 
Marçais, B., Vuorinen, M., Tsopelas, P., Koltay, A., Halasz, A., La Porta, N., Anselmi, N., Kiesnere, R., Markovskaja, S., Kačergius, A., Papazova-Anakieva, I., Risteski, M., Sotirovski, K., Lazarević, J., Solheim, H., Boroń, P., Bragança, H., Chira, D., Musolin, D. L., Selikhovkin, A. V., Bulgakov, T. S., Keča, N., Karadžić, D., Galovic, V., Pap, P., Markovic, M., Pajnik, L. P., Vasic, V., Ondrušková, E., Piškur, B., Sadiković, D., Diez, J. J., Solla, A., Millberg, H., Stenlid, J., Angst, A., Queloz, V., Lehtijärvi, A., Doğmuş-Lehtijärvi, H. T., Oskay, F., Davydenko, K., Meshkova, V., Craig, D., Woodward, S., and Barnes, I. 2016. Global geographic distribution and host range of Dothistroma species: A comprehensive review. For. Pathol. 46:408-442.

Dubin, J. 1965. Una breve nota sobre Dothistroma pini Hulbary: Tizon de la aguja del Pinus radiata D. don en Chile. Publicaciones cientificas de la Universidad Austral de Chile.

Elshire, R. J., Glaubitz, J. C., Sun, Q., Poland, J. A., Kawamoto, K., Buckler, and Mitchell, S. E. 2011. A robust, simple genotyping-by-sequencing (GBS) approach for high diversity species. PLoS One 6:e19379.

Ennos, R. A., Sjökvist, E. I., Piotrowska, M. J., Riddell, C., and Hoebe, P. N. 2020. Using genome resequencing to investigate racial structure, genetic diversity, sexual reproduction and hybridisation in the pine pathogen Dothistroma septosporum. Fungal Ecol. 45:100921.

Evans, H. C. 1984. The genus Mycosphaerella and its anamorphs Cercoseptoria, Dothistroma and Lecanosticta on pines. CMI Mycol. Pap. No. 153. Commonwealth Mycological Institute, Surrey, U.K.

Excoffier, L., and Lischer, H. E. L. 2010. Arlequin suite ver 3.5: A new series of programs to perform population genetics analyses under Linux and Windows. Mol. Ecol. Resour. 10:564-567.

Feau, N., Ramsfield, T. D., Myrholm, C. L., Tomm, B., Cerezke, H. F., Benowicz, A., Samis, E., Romano, A., Dale, A. L., Capron, A., Heinzelmann, R., and Hamelin, R. C. DNA-barcoding identification of Dothistroma septosporum on Pinus contorta var. latifolia, P. banksiana and their hybrid in northern Alberta, Canada. Can. J. Plant Pathol. In press. doi: 10.1080/07060661.2020.1829065

Frichot, E., Mathieu, F., Trouillon, T., Bouchard, G., and François, O. 2014. Fast and efficient estimation of individual ancestry coefficients. Genetics 196:973-983.

Gibson, I. A. S., Christensen, P. S., and Munga, F. M. 1964. First observation in Kenya of a foliage disease of pines caused by Dothistroma pini Hulbary. Commonwealth Forestry Association. https://www.jstor.org/stable/42603100

Gladieux, P., Feurtey, A., Hood, M. E., Snirc, A., Clavel, J., Dutech, C., Roy, M., and Giraud, T. 2015. The population biology of fungal invasions. Mol. Ecol. 24:1969-1986.

Gladieux, P., Ravel, S., Rieux, A., Cros-Arteil, S., Adreit, H., Milazzo, J., Thierry, M., Fournier, E., Terauchi, R., and Tharreau, D. 2018. Coexistence of multiple endemic and pandemic lineages of the rice blast pathogen. MBio 9:e01806-17.

Godbout, J., Fazekas, A., Newton, C. H., Yeh, F. C., and Bousquet, J. 2008. Glacial vicariance in the Pacific Northwest: Evidence from a lodgepole pine mitochondrial DNA minisatellite for multiple genetically distinct and widely separated refugia. Mol. Ecol. 17:2463-2475.

Gordon, A., and Hannon, G. 2012. FASTX-Toolkit. http://hannonlab.cshl.edu/ fastx_toolkit/

Government of British Columbia. Lodgepole Pine Tree Breeding Program. https://www2.gov.bc.ca/gov/content/industry/forestry/managing-our-forestresources/tree-seed/forest-genetics/tree-breeding-improvement/lodgepolepine

Groenewald, M., Barnes, I., Bradshaw, R. E., Brown, A. V., Dale, A., Groenewald, J. Z., Lewis, K. J., Wingfield, B. D., Wingfield, M. J., and Crous, P. W. 2007. Characterization and distribution of mating type genes in the Dothistroma needle blight pathogens. Phytopathology 97:825-834.

Gutenkunst, R. N., Hernandez, R. D., Williamson, S. H., and Bustamante, C. D. 2009. Inferring the joint demographic history of multiple populations from multidimensional SNP frequency data. PLoS Genet. 5:e1000695.

Herath, P., Beauseigle, S., Dhillon, B., Ojeda, D. I., Bilodeau, G., Isabel, N., Gros-Louis, M.-C., Kope, H., Zegln, S., Hamelin, R. C., and Feau, N. 2016. Anthropogenic signature in the incidence and distribution of an emerging pathogen of poplars. Biol. Invasions 18:1147-1161.

Hill, W. G., and Robertson, A. 1968. Linkage disequilibrium in finite populations. Theor. Appl. Genet. 38:226-231.

Jakobsson, M., and Rosenberg, N. A. 2007. CLUMPP: A cluster matching and permutation program for dealing with label switching and multimodality in analysis of population structure. Bioinformatics 23:1801-1806.

Kabir, M. S., Ganley, R. J., and Bradshaw, R. E. 2015. The hemibiotrophic lifestyle of the fungal pine pathogen Dothistroma septosporum. For. Pathol. 45:190-202.

Kamvar, Z. N., Tabima, J. F., and Grünwald, N. J. 2014. Poppr: An R package for genetic analysis of populations with clonal, partially clonal, and/or sexual reproduction. PeerJ 2:e281.
Kasuga, T., White, T. J., and Taylor, J. W. 2002. Estimation of nucleotide substitution rates in eurotiomycete fungi. Mol. Biol. Evol. 19: 2318-2324.

Li, H. 2011. A statistical framework for SNP calling, mutation discovery, association mapping and population genetical parameter estimation from sequencing data. Bioinformatics 27:2987-2993.

Li, H., and Durbin, R. 2009. Fast and accurate short read alignment with Burrows-Wheeler transform. Bioinformatics 25:1754-1760.

MacDonald, G. M., and Cwynar, L. C. 1985. A fossil pollen based reconstruction of the late Quaternary history of lodgepole pine (Pinus contorta ssp. latifolia) in the western interior of Canada. J. For. Res. 15: 1039-1044.

MacLachlan, I. R., Wang, T., Hamann, A., Smets, P., and Aitken, S. N. 2017. Selective breeding of lodgepole pine increases growth and maintains climatic adaptation. For. Ecol. Manage. 391:404-416.

Mix, A. C., Bard, E., and Schneider, R. 2001. Environmental processes of the ice age: Land, oceans, glaciers (EPILOG). Q. Sci. Rev. 20:627-657.

Mullett, M. S., Brown, A. V., Fraser, S., Baden, R., and Tubby, K. V. 2017. Insights into the pathways of spread and potential origins of Dothistroma septosporum in Britain. Fungal Ecol. 26:85-98.

Mullett, M. S., Tubby, K. V., Webber, J. F., and Brown, A. V. 2016. A reconsideration of natural dispersal distances of the pine pathogen Dothistroma septosporum. Plant Pathol. 65:1462-1472.

Ohm, R. A., Feau, N., Henrissat, B., Schoch, C. L., Horwitz, B. A., Barry, K. W., Condon, B. J., Copeland, A. C., Dhillon, B., Glaser, F., Hesse, C. N., Kosti, I., LaButti, K., Lindquist, E. A., Lucas, S., Salamov, A. A., Bradshaw, R. E., Ciuffetti, L., Hamelin, R. C., Kema, G. H. J., Lawrence, C., Scott, J. A., Spatafora, J. W., Turgeon, B. G., de Wit, P. J. G. M., Zhong, S., Goodwin, S. B., and Grigoriev, I. V. 2012. Diverse lifestyles and strategies of plant pathogenesis encoded in the genomes of eighteen Dothideomycetes fungi. PLoS Pathog. 8:e1003037.

Ozturk, I. K., Chettri, P., Dupont, P.-Y., Barnes, I., McDougal, R. L., Moore, G. G., Sim, A., and Bradshaw, R. E. 2017. Evolution of polyketide synthesis in a Dothideomycete forest pathogen. Fungal Genet. Biol. 106:42-50.

Pautasso, M., Schlegel, M., and Holdenrieder, O. 2015. Forest health in a changing world. Microb. Ecol. 69:826-842.

Piotrowska, M. J., Riddell, C., Hoebe, P. N., and Ennos, R. A. 2017. Planting exotic relatives has increased the threat posed by Dothistroma septosporum to the Caledonian pine populations of Scotland. Evol. Appl. 11: 350-363.

R Core Team. 2013. R: A Language and Environment for Statistical Computing. R Foundation for Statistical Computing, Vienna, Austria.

Sakalidis, M. L., Feau, N., Dhillon, B., and Hamelin, R. C. 2016. Genetic patterns reveal historical and contemporary dispersal of a tree pathogen. Biol. Invasions 18:1781-1799.

Shaw, J., Piper, D. J. W., Fader, G. B. J., King, E. L., Todd, B. J., Bell, T., Batterson, M. J., and Liverman, D. G. E. 2006. A conceptual model of the deglaciation of Atlantic Canada. Q. Sci. Rev. 25:2059-2081.

Sonah, H., Bastien, M., Iquira, E., Tardivel, A., Légraré, G., Boyle, B., Normandeau, É., Laroche, J., Larose, S., Jean, M., and Belzile, F. 2013. An improved genotyping by sequencing (GBS) approach offering increased versatility and efficiency of SNP discovery and genotyping. PLoS One 8: e54603.

Stamatakis, A. 2014. RAxML version 8: A tool for phylogenetic analysis and post-analysis of large phylogenies. Bioinformatics 30:1312-1313.

Swofford, D. L. 2003. PAUP*. Phylogenetic Analysis using Parsimony and Other Methods. Sinauer Associates, Sunderland, MA, U.S.A.

Tabima, J. F., Søndreli, K. L., Keriö, S., Feau, N., Sakalidis, M. L., Hamelin, R. C., and LeBoldus, J. M. 2020. Population genomic analyses reveal connectivity via human-mediated transport across Populus plantations in North America and an undescribed subpopulation of Sphaerulina musiva. Mol. Plant-Microbe Interact. 33:189-199.

Trumbore, S., Brando, P., and Hartmann, H. 2015. Forest health and global change. Science 349:814-818.

Ukrainetz, N. K., Yanchuk, A. D., and Mansfield, S. D. 2018. Climatic drivers of genotype-environment interactions in lodgepole pine based on multienvironment trial data and a factor analytic model of additive covariance. Can. J. For. Res. 48:835-854.

van Sickle, G. A., Fiddick, R. L., and Wood, C. S. 2001. The forest insect and disease survey in the pacific region. J. Entomol. Soc. B.C. 98:169-176.

Vercken, E., Fontaine, M. C., Gladieux, P., Hood, M. E., Jonot, O., and Giraud, T. 2010. Glacial refugia in pathogens: European genetic structure of anther smut pathogens on Silene latifolia and Silene dioica. PLoS Pathog. 6: e1001229.

Ward, B. C., Wilson, M. C., Nagorsen, D. W., Nelson, D. E., Driver, J. C., and Wigen, R. J. 2003. Port Eliza cave: North American West Coast interstadial environment and implications for human migrations. Q. Sci. Rev. 22: 1383-1388. 
Watt, M. S., Kriticos, D. J., Alcaraz, S., Brown, A. V., and Leriche, A. 2009. The hosts and potential geographic range of Dothistroma needle blight. For. Ecol. Manage. 257:1505-1519.

Welsh, C., Lewis, K., and Woods, A. 2009. The outbreak history of Dothistroma needle blight: An emerging forest disease in northwestern British Columbia, Canada. Can. J. For. Res. 39:2505-2519.

Woods, A., Coates, K. D., and Hamann, A. 2005. Is an unprecedented Dothistroma needle blight epidemic related to climate change? Bioscience 55:761-769.

Woods, A. J. 2003. Species diversity and forest health in northwest British Columbia. For. Chron. 79:892-897.
Woods, A. J., Martín-García, J., Bulman, L., Vasconcelos, M. W., Boberg, J., La Porta, N., Peredo, H., Vergara, G., Ahumada, R., Brown, A., Diez, J., and Stenlid, J. 2016. Dothistroma needle blight, weather and possible climatic triggers for the disease's recent emergence. For. Pathol. 46:443-452. Zheng, X., Levine, D., Shen, J., Gogarten, S. M., Laurie, C., and Weir, B. S. 2012. A high-performance computing toolset for relatedness and principal component analysis of SNP data. Bioinformatics 28:3326-3328.

Zhu, Y. O., Siegal, M. L., Hall, D. W., and Petrov, D. A. 2014. Precise estimates of mutation rate and spectrum in yeast. Proc. Natl. Acad. Sci. U.S.A. 111:E2310-E2318. 